\title{
Maternal Mortality in Two Reference Hospitals in the City of Yaounde (Cameroon): Epidemiological, Clinical and Prognostic Aspects
}

\author{
Armand Kamga Talom ${ }^{*}$, Florent Fouelifack Ymele ${ }^{2,3}$, Edmond Mesumbe Nzene1, \\ Jeanne Fouedjio1,3, Pascal Foumane ${ }^{1,4}$ \\ ${ }^{1}$ Department of Gynecology and Obstetrics, Faculty of Medicine and Biomedical Sciences, University of Yaounde I, Yaounde, \\ Cameroon \\ ${ }^{2}$ Higher Institute of Medical Technology, Yaounde Central Hospital, Yaounde, Cameroon \\ ${ }^{3}$ Yaounde Central Hospital, Yaounde, Cameroon \\ ${ }^{4}$ Yaounde Gyneco-Obstetric and Pediatric Hospital, Yaounde, Cameroon \\ Email: ^kamtalar@gmail.com, yfouelifack@gmail.com, edmodmesumbe88@gmail.com, fouedjiojeanne@yahoo.fr, \\ pfoumane2004@yahoo.fr
}

How to cite this paper: Kamga Talom, A., Ymele, F.F., Nzene, E.M., Fouedjio, J. and Foumane, P. (2021) Maternal Mortality in Two Reference Hospitals in the City of Yaounde (Cameroon): Epidemiological, Clinical and Prognostic Aspects. Open Journal of Obstetrics and Gynecology, 11, 610-625. https://doi.org/10.4236/ojog.2021.115057

Received: March 18, 2021

Accepted: May 22, 2021

Published: May 25, 2021

Copyright (c) 2021 by author(s) and Scientific Research Publishing Inc. This work is licensed under the Creative Commons Attribution International License (CC BY 4.0).

http://creativecommons.org/licenses/by/4.0/

\begin{abstract}
Objectives: The objective of this work was to determine the epidemiological, clinical and prognostic aspects of maternal mortality (MM) in the city of Yaounde. Methods: We conducted a descriptive cross-sectional study with retrospective data collection of maternal deaths according to the World Health Organization (WHO) definition, from January 1, 2017 to December 31, 2019, in two tertiary centers of Yaounde: The Yaounde Gynaeco-Obstetric and Paediatric Hospital (YGOPH) and the Yaounde Central Hospital (YCH). Results: During the study period, 208 maternal deaths were identified, with $4 / 5$ (78.4\%) from referred cases. The MM ratio was 1532.8 per 100,000 live births (LB) vs. 609.5 per 100,000 live births at YCH and YGOPH respectively. The Main causes where haemorrhage (49\%) followed by hypertensive diseases and their complications (21.2\%), maternal mortality was associated with $50 \%$ of cases of foetal or neonatal deaths $(57.4 \%$ in $\mathrm{YCH}$ vs $28.3 \%$ in $\mathrm{YGOPH}$, $\mathrm{P}<0.001)$. Health service systems were related to MM. Conclusion: Our study shows a large increase in maternal mortality ratios in $\mathrm{YCH}$ and YGOPH maternities since 2017. The main causes of MM found were haemorrhage followed by hypertensive diseases. These causes can be prevented. Our health systems should be improved if we want to significantly reduce the maternal mortality ratio.
\end{abstract}


Keywords

Maternal Mortality, Tertiary Centers, Yaounde, Cameroon

\section{Introduction}

The World Health Organization (WHO) defines maternal mortality in the tenth revision of the International Classification of Diseases (ICD-10) as "the death of a woman during pregnancy or within 42 days of its termination, regardless of duration or location, from any cause determined or aggravated by pregnancy or pregnancy-related causes, but not accidental or malicious" [1]. Approximately 830 women die every day worldwide from preventable causes related to pregnancy and childbirth [2]. Central Africa is home to three of the countries with the highest mortality rates in the world: Central African Republic with 882 per 100,000 live births, Chad with 856 per 100,000 live births and Nigeria with 814 per 100,000 live births [3]. According to the recent Demographic Health Survey in Cameroon (EDSC-V), the maternal mortality rate dropped from 728 in 2004-2011 to 467 in 2012-2018 per 100,000 live births, i.e. a reduction of 51.9\% [4]. These overwhelming figures, mentioned above, show that maternal mortality is a major and urgent public health problem in developing countries, particularly in Central Africa. And even if we note a decrease in the maternal mortality rate in Cameroon since 2004, it appears that it remains a matter of concern for our society. Many risk factors for MM have already been identified by various studies: age, parity, age-parity combination, low socio-economic status, singlehood and in some cases marriage (too many children, too early, too late and too close together). The authors' objective was to determine maternal mortality in two tertiary centers in Yaounde with a high attendance potential.

\section{Material and Method}

\subsection{Framework}

The two hospitals that are the subject of our study are major structures of obstetric care in the city.

The Yaounde Gynaeco-Obstetric and Paediatric Hospital is a reference health facility created in 2002 and specialises in the care of mothers and children. Its gynaecology-obstetrics department has a capacity of 34 inpatient beds, three delivery tables, four operating theatres with two laparoscopy columns, and an admission room adjacent to the delivery room. The service carries out an average of 3015 deliveries per year. In an environment marked by limited financial resources and the absence of social security, obstetric emergencies benefited during the study period from the permanent availability of surgical and anaesthetic teams. The medical team consisted of eleven obstetrician-gynaecologists, three permanent anaesthetists, a general practitioner, nurses and midwives at the time of the study. They provide a permanent on-call service in their respective departments and are assisted by residents from their respective specialties. 
The Yaounde central hospital is a reference hospital, created in 1930 and functional in 1933. Its maternity ward is very well attended, divided into two parts, namely Clinic A and Clinic B. The maternity ward carries out an average of 3664 deliveries per year. Its medical team at the time of the study consisted of eleven gynaecologist-obstetricians, two anaesthetist-animators, a permanent general practitioner, residents in gynaecology-obstetrics and anaesthesia-animation, four nurses specialised in reproductive health, four state-registered nurses, thirty-nine licensed nurses.

The supply of essential medicines and consumable materials is ensured by the pharmacy of each of these two hospitals. Their availability is uncertain, requiring direct financial participation by the patients. It should also be noted that both hospitals have a blood bank.

\subsection{Methods}

This was a descriptive cross-sectional study with retrospective data collection that was carried out in the two above mentioned hospitals. All maternal deaths meeting the WHO's definition that occurred between $1^{\text {st }}$ January 2017 and $31^{\text {st }}$ December 2019 were included. The data collected on a data sheet concerned socio-demographic variables; age, occupation, ethnicity, education level, marital status, occupation, time of entry, place of origin, referring facility, transport condition, mode of admission, reason for referral or reason for admission if patient not referred... Clinico-obstetrical variables; Gravida, parity Family history, term of pregnancy, pregnancy follow-up, uterine height, uterine contractions, fetal heart sounds, pervaginal bleeding, Bishop score, state of membranes and amniotic fluid, presentation, date and time of death, time to care... The main aetiologies and variables related to the circumstances of death; Causes of death, identified risk factors, time of death... as well as factors contributing to maternal death and fetal prognosis; Community and health service factors, status of the newborn, avoidability of death. We took inspiration from some survey templates used in similar studies, which we tested and adapted to our context. All survey were anonymous and confidential. Prior authorisation had been obtained from the National Ethics Committee and the management of both hospitals. The data were then computerised and analysed using CSPro 7.3 and Excel 2016 softwares.

\section{Results}

\subsection{Frequencies (Figure 1)}

During the study period we recorded 155 and 53 maternal deaths in $\mathrm{YCH}$ and YGOPH maternity wards respectively. During the same period, 10,112 and 8695 live births (LB) were respectively registered in these 2 maternity hospitals, giving a maternal mortality ratio of 1532.8 and 609.5 per 100,000 LB respectively. The evolution of maternal mortality ratios over the last 3 years is presented in Figure 1. During the last three years, the maternal mortality ratio was higher in $\mathrm{YCH}$ (1532.8 per 100,000 LB). It was higher in YCH in 2019 (1997.6 per 100,000 LB) and in YGOPH in 2018 (746.5 per 100,000 LB). 


\section{Trends in the maternal mortality}

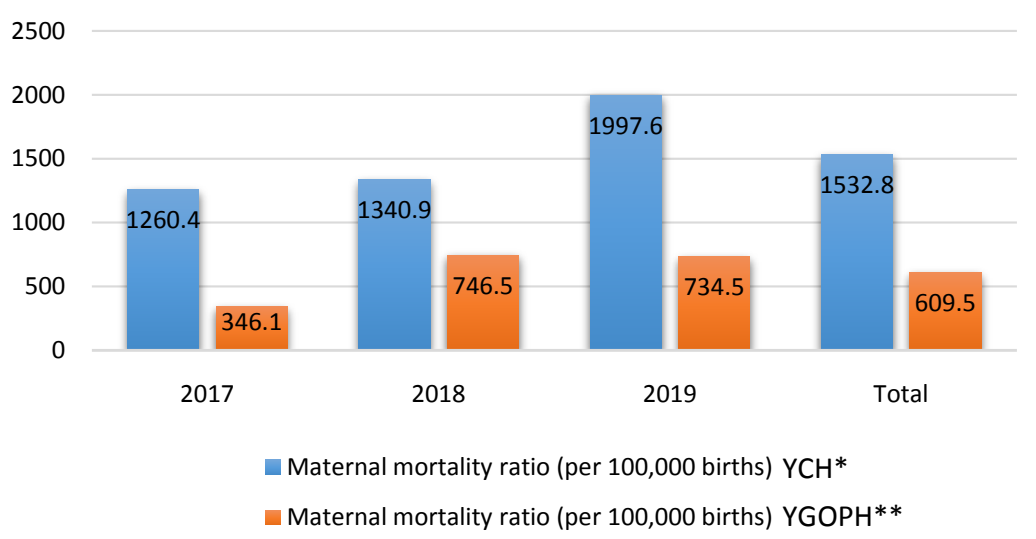

Figure 1. Trends in the maternal mortality ratio by year. ${ }^{*}=$ Yaounde Central Hospital; ** = Yaounde Gynaeco-Obstetric and Paediatric Hospital.

\subsection{Socio-Demographic Characteristics (Table 1)}

Table 1. Distribution of maternal deaths by age and marital status.

\begin{tabular}{|c|c|c|c|c|}
\hline Variables & $\begin{array}{c}\text { Total } \\
\mathrm{N}=208(\%)\end{array}$ & $\begin{array}{c}\mathrm{YCH}^{\mathrm{a}} \\
\mathrm{N}=155(\%)\end{array}$ & $\begin{array}{c}\text { YGOPH }^{\mathrm{b}} \\
\mathrm{N}=53(\%)\end{array}$ & $P$-value \\
\hline \multicolumn{5}{|l|}{ Age groups (years) } \\
\hline$[15-20[$ & $17(8.2)$ & $16(10.3)$ & $1(1.9)$ & $<0.001$ \\
\hline$[20-25[$ & $48(23.1)$ & $35(22.6)$ & $13(24.5)$ & 0.771 \\
\hline$[25-30[$ & $40(19.2)$ & $30(19.4)$ & $10(18.9)$ & 0.938 \\
\hline$[30-35[$ & $57(27.4)$ & $43(27.7)$ & $14(26.4)$ & 0.993 \\
\hline$[35-40[$ & $38(18.3)$ & $27(17.4)$ & $11(20.8)$ & 0.588 \\
\hline$\geq 40$ & $8(3.8)$ & $4(2.6)$ & $4(7.5)$ & 0.105 \\
\hline \multicolumn{5}{|l|}{ Marital status } \\
\hline Married & $82(39.1)$ & $58(37.4)$ & $24(45.3)$ & 0.312 \\
\hline Single & $119(57.2)$ & $90(58)$ & $29(54.7)$ & 0.670 \\
\hline Widow & $1(0.5)$ & $1(0.6)$ & $0(0)$ & 1.000 \\
\hline N.I ${ }^{c}$ & $6(2.9)$ & $6(3.9)$ & $0(0)$ & 0.341 \\
\hline \multicolumn{5}{|l|}{ Occupation } \\
\hline Housewife & $85(40.9)$ & $61(39.4)$ & $24(45.3)$ & 0.449 \\
\hline University student & $19(9.1)$ & $17(11)$ & $2(3.8)$ & 0.167 \\
\hline Shopkeeper & $18(8.7)$ & $13(8.4)$ & $5(9.4)$ & 0.782 \\
\hline College student & $17(8.2)$ & $14(9)$ & $3(5.7)$ & 0.569 \\
\hline Teacher & $9(4.3)$ & $5(3.2)$ & $4(7.5)$ & 0.237 \\
\hline Seamstress & $8(3.8)$ & $6(3.9)$ & $2(3.8)$ & 1.000 \\
\hline Hairdresser & $7(3.4)$ & $6(3.9)$ & $1(1.9)$ & 0.681 \\
\hline Others $^{\mathrm{d}}$ & $22(10.5)$ & $15(9.6)$ & $11(13.2)$ & 0.354 \\
\hline N.I ${ }^{c}$ & $23(11.1)$ & 18 (11.6) & $5(9.4)$ & 0.802 \\
\hline
\end{tabular}

$\mathbf{a}=$ Yaounde Central Hospital; $\mathbf{b}=$ Yaounde Gynaeco-Obstetric and Paediatric Hospital; $\mathbf{c}=$ Not informed; $\mathbf{d}=$ Waitress, secretary, nurse, receptionist, telecom consultant, concierge, babysitter, marketing assistant, tax auditor, beautician, hotel manager, civil servant, call-box operator. 
Of the 208 maternal deaths identified during the study period. $27.4 \%$ were aged between 30 and 34 years, while adolescents (age $<20$ years) made up $8.2 \%$ of our sample with a significant difference in the two hospitals. Furthermore, $5.2 \%$ of our deaths involved women aged 40 and over. $65.5 \%$ were not officially married and $51.7 \%$ were housewives without paid employment. In terms of obstetrical history, maternal death seemed to occur more often among women who had already given birth to 1 to 3 children $(65.6 \%)$.

The average age in the population of our study was $28.8 \pm 6.8$ with extremes ranging from 15 to 49 years. The mean ages were $28.3 \pm 6.6$ and $30.2 \pm 7.2$ respectively for $\mathrm{YCH}$ and YGOPH $(\mathrm{P}=0.081)$. The most represented age group was that of [30 - 35 years old], i.e. 27.4\% (27.7\% for YCH vs. $26.4 \%$ for HGOPY, $\mathrm{P}=0.993$ ). While adolescent girls (age $<20$ years) made up $8.2 \%$ of our sample with a significant difference in both hospitals $(10.3 \%$ in $\mathrm{YCH}$ vs. $1.9 \%$ in $\mathrm{YGOPH}$, $\mathrm{P}<0.001$ ). In addition, $57.2 \%$ were married and $40.9 \%$ were housewives without paid employment, with no significant difference in the two hospitals.

\subsection{Obstetrical Characteristics and Pregnancy Follow-Up (Table 2)}

Table 2. Obstetrical history and pregnancy follow-up.

\begin{tabular}{|c|c|c|c|c|}
\hline Variables & $\begin{array}{c}\text { Total } \\
\mathrm{N}=208(\%)\end{array}$ & $\begin{array}{c}\mathrm{YCH}^{\mathrm{a}} \\
\mathrm{N}=155(\%)\end{array}$ & $\begin{array}{c}\text { YGOPH }^{\mathrm{b}} \\
\mathrm{N}=53(\%)\end{array}$ & $\mathrm{P}$-value \\
\hline \multicolumn{5}{|l|}{ Parity } \\
\hline 0 & $41(19.7)$ & $34(21.9)$ & $7(13.2)$ & 0.168 \\
\hline 1 & $42(20.2)$ & $26(16.8)$ & $16(30.2)$ & 0.036 \\
\hline $2-3$ & $63(30.3)$ & $44(28.4)$ & $19(35.8)$ & 0.307 \\
\hline $4-5$ & $42(20.2)$ & $34(21.9)$ & $8(15.1)$ & 0.284 \\
\hline$>5$ & $17(8.2)$ & $14(9)$ & $3(5.7)$ & 0.569 \\
\hline$N \cdot R^{g}$ & $3(1.4)$ & $3(1.9)$ & $0(0)$ & 0.572 \\
\hline \multicolumn{5}{|l|}{ Number of $A^{\prime N C}$} \\
\hline 0 & $89(42.8)$ & $69(44.5)$ & $20(37.7)$ & 0.389 \\
\hline 1 & $8(3.8)$ & $7(4.5)$ & $1(1.9)$ & 0.683 \\
\hline 2 & $28(13.5)$ & $18(11.6)$ & $10(18.9)$ & 0.182 \\
\hline 3 & $33(15.9)$ & $26(16.8)$ & $7(13.2)$ & 0.540 \\
\hline$\geq 4$ & $50(24)$ & $35(22.6)$ & $15(28.3)$ & 0.400 \\
\hline \multicolumn{5}{|l|}{ Place of ANC } \\
\hline$D M C^{d}$ & $8(6.7)$ & $8(9.3)$ & $0(0)$ & 0.104 \\
\hline $\mathrm{DH}^{\mathrm{e}}$ & $8(6.7)$ & $5(5.8)$ & $3(9.1)$ & 0.683 \\
\hline Private $\mathrm{HC}^{\mathrm{f}}$ & $64(50)$ & $43(50)$ & $21(63.6)$ & 0.220 \\
\hline Faith-based HC & $28(23.5)$ & $22(25.6)$ & $6(18.2)$ & 0.475 \\
\hline Reference hospital & $11(9.2)$ & $8(9.3)$ & $3(9.1)$ & 1.000 \\
\hline Not monitored & $89(42.8)$ & $69(44.5)$ & $20(37.7)$ & 0.389 \\
\hline
\end{tabular}

$\mathbf{a}=$ Yaounde Central Hospital; $\mathbf{b}=$ Yaounde Gynaeco-Obstetric and Paediatric Hospital Yaounde; $\mathbf{c}=$ Antenatal Care; $\mathbf{d}=$ District Medical Centre; $\mathbf{e}=$ District Hospital; $\mathbf{f}=$ health centre; $\mathbf{g}=$ Not informed. 
In terms of obstetrical history, the mean parity in the population of our study was $2.4 \pm 2.1$ with extremes ranging from 0 to 9 ; i.e. a mean parity of $2.5 \pm 2.1$ and $2.2 \pm 1.9$ for $\mathrm{YCH}$ and $\mathrm{YGOPH}$ respectively $(\mathrm{P}=0.469)$. The paucipara were the most represented $(30.3 \%)$ of cases of maternal death: $(28.4 \%$ for $\mathrm{YCH}$ vs $35.8 \%$ for YGOPH, $\mathrm{P}=0.307$ ). In our series, $76 \%$ of the women who died had not completed the minimum of 4 Antenal cares (ANCs) recommended by the WHO, with no significant difference in the two hospitals. More specifically, almost half of the patients, i.e. $42.8 \%$, had no prenatal follow-up (44.5\% at $\mathrm{YCH}$ vs. $37.7 \%$ at $Y G O P H ; P=0.389) .50 \%$ of patients who had made their prenatal visits did so in private health centres (i.e. $50 \%$ in $\mathrm{YCH}$ vs $63.6 \%$ in $\mathrm{YGOPH}$; $\mathrm{P}=$ $0.220)$.

\subsection{Admission Context (Table 3)}

Table 3. Distribution of maternal deaths by context of admission.

\begin{tabular}{|c|c|c|c|c|}
\hline Variables & $\begin{array}{c}\text { Total } \\
\mathrm{N}=208(\%)\end{array}$ & $\begin{array}{c}\mathrm{YCH}^{\mathrm{a}} \\
\mathrm{N}=155(\%)\end{array}$ & $\begin{array}{c}\text { YGOPH }^{\mathrm{b}} \\
\mathrm{N}=53(\%)\end{array}$ & P-value \\
\hline \multicolumn{5}{|l|}{ Mode of admission } \\
\hline $\begin{array}{l}\text { Coming on her own or brought } \\
\text { by the family }\end{array}$ & $39(18.8)$ & $25(16.1)$ & $14(26.4)$ & 0.075 \\
\hline Referred & $168(78.4)$ & $124(80)$ & $39(71.6)$ & 0.327 \\
\hline deceased upon arrival & $6(2.9)$ & $6(3.9)$ & $0(0)$ & 0.341 \\
\hline \multicolumn{5}{|l|}{ Referent structure } \\
\hline $\mathrm{DMC}^{\mathrm{c}}$ & $21(10.1)$ & $19(12.3)$ & $2(3.8)$ & 0.111 \\
\hline $\mathrm{DH}^{\mathrm{d}}$ & $24(11.5)$ & $20(12.9)$ & $4(7.5)$ & 0.292 \\
\hline Private $\mathrm{HC}^{\mathrm{e}}$ & $78(37.5)$ & $55(35.5)$ & $23(43.4)$ & 0.304 \\
\hline Faith-based HC & $30(14.4)$ & $23(14.8)$ & $7(13.2)$ & 0.696 \\
\hline Reference hospital & $9(4.3)$ & $6(3.9)$ & $3(5.7)$ & 0.770 \\
\hline N.I $^{\mathrm{f}}$ & $46(22.1)$ & $32(20.6)$ & $14(26.4)$ & 0.382 \\
\hline \multicolumn{5}{|l|}{ Mode of transport } \\
\hline Ambulance & $5(2.4)$ & $4(2.6)$ & $1(1.9)$ & 1.000 \\
\hline Taxi & $75(36.1)$ & $65(41.9)$ & $10(18.9)$ & 0.003 \\
\hline Personal car & $34(16.3)$ & $26(16.8)$ & $8(15.1)$ & 0.775 \\
\hline Motobike & $1(0.5)$ & $0(0)$ & $1(1.9)$ & 0.255 \\
\hline N.I & $93(44.7)$ & $60(38.7)$ & $33(62.3)$ & 0.003 \\
\hline \multicolumn{5}{|l|}{$\mathrm{PVL}^{\mathrm{g}}$} \\
\hline Yes & $84(40.4)$ & $65(41.9)$ & $19(35.8)$ & 0.436 \\
\hline No & $91(43.8)$ & $67(43.2)$ & $24(45.3)$ & 0.794 \\
\hline N.I & $33(15.9)$ & $23(14.8)$ & $10(18.9)$ & 0.488 \\
\hline
\end{tabular}

$\mathbf{a}=$ Yaounde Central Hospital; $\mathbf{b}=$ Yaounde Gynaeco-Obstetric and Paediatric Hospital; $\mathbf{c}=$ District Medical Centre; $\mathbf{d}=$ District Hospital; $\mathbf{e}=$ health centre; $\mathbf{f}=$ Not informed; $\mathbf{g}=$ Peripheral Venous Line. 
In our series, $78.4 \%$ of the women who died were referred, of which $80 \%$ were referred in $\mathrm{YCH}$ and $71.6 \%$ in YGOPH. Among these patients, 37.5\% were referred from a private health centres $(35.5 \%$ to $\mathrm{YCH}$ vs $43.4 \%$; $\mathrm{P}=0.304)$. The most common mode of transport used for reported deaths was taxi in $36.1 \%$ (41.9\% to $\mathrm{YCH}$ vs. $18.9 \%$; $\mathrm{P}=0.003$ ). Finally, $43.8 \%$ of the women who died did not have a Peripheral Venous Line (43.2\% in $\mathrm{YCH}$ vs. $45.3 \%$; $\mathrm{P}=0.794)$.

\subsection{Etiologies of Maternal Death (Table 4)}

Direct obstetrical causes were the most frequent with 175 cases $(84.1 \%)$. The frequency of obstetrical causes was fairly constant in both hospitals, $84.5 \%$ in $\mathrm{YCH}$ and $83 \%$ in HGOPY. Haemorrhage was the first direct obstetric cause of maternal death in $49 \%$ with a significant difference in the two hospitals: $(55.5 \%$ in $\mathrm{YCH}$ and $30.2 \%$ in YGOPH; P $<0.001$ ). The second direct obstetrical cause of maternal death was represented by illnesses and complications related to hypertension in $21.2 \%$ of cases, with a significant difference between the two hospitals: $(15.5 \%$ at $\mathrm{YCH}$ and $35.8 \%$ at $\mathrm{YGOPH} ; \mathrm{P}=0.002)$. Pre-eclampsia and eclampsia were predominantly represented with $11.1 \%$ in both hospitals. Encephalopathy was the first indirect obstetrical cause of maternal death in 7 cases, i.e. 3.4\% (2.6\% in $\mathrm{YCH}$ and $5.7 \%$ in $\mathrm{YGOPH} ; \mathrm{P}=0.283)$.

Table 4. Distribution by direct and indirect obstetric causes.

\begin{tabular}{|c|c|c|c|c|}
\hline Obstétrical causes & $\begin{array}{c}\text { Total } \\
\mathrm{N}=208(\%)\end{array}$ & $\begin{array}{c}\mathrm{YCH}^{\mathrm{a}} \\
\mathrm{N}=155(\%)\end{array}$ & $\begin{array}{c}\text { YGOPH }^{\mathrm{b}} \\
\mathrm{N}=53(\%)\end{array}$ & P-value \\
\hline Direct causes & $175(84.1)$ & $131(84.5)$ & $44(83)$ & 0.779 \\
\hline Haemorrhage & $102(49)$ & $86(55.5)$ & $16(30.2)$ & $<0.001$ \\
\hline Uterine atony & $32(15.4)$ & $27(17.4)$ & $5(9.4)$ & 0.164 \\
\hline Uterine rupture & $24(11.5)$ & $22(14.2)$ & $2(3.8)$ & 0.040 \\
\hline $\mathrm{DIC}^{\mathrm{c}}$ & $13(6.3)$ & $10(6.5)$ & $3(5.7)$ & 0.837 \\
\hline $\mathrm{EP}^{\mathrm{d}}$ & $8(3.8)$ & $6(3.9)$ & $2(3.8)$ & 0.975 \\
\hline Cervical tear & $7(3.4)$ & $6(3.9)$ & $1(1.9)$ & 0.489 \\
\hline Abortion & $6(2.8)$ & $5(3.2)$ & $1(1.9)$ & 0.615 \\
\hline Placental retention & $5(2.4)$ & $5(3.2)$ & $0(0)$ & 0.171 \\
\hline Placenta previa & $4(1.9)$ & $4(2.6)$ & $0(0)$ & 0.238 \\
\hline Placental abruption & $3(1.4)$ & $1(0.6)$ & $2(3.8)$ & 0.099 \\
\hline $\mathrm{HBP}^{\mathrm{e}}$ & $44(21.2)$ & $24(15.5)$ & $19(35.8)$ & 0.002 \\
\hline Eclampsia & $23(11.1)$ & $14(9)$ & $9(17)$ & 0.111 \\
\hline Preeclampsia & $12(5.8)$ & $7(4.5)$ & $5(9.4)$ & 0.185 \\
\hline HELLP $^{f}$ syndrom & $6(2.8)$ & $2(1.3)$ & $4(7.5)$ & 0.019 \\
\hline Stroke & $1(0.5)$ & $0(0)$ & $1(1.9)$ & 0.087 \\
\hline $\mathrm{AOL}^{\mathrm{g}}$ & $1(0.5)$ & $1(0.6)$ & $0(0)$ & 0.136 \\
\hline Infections & $17(8.2)$ & $13(8.4)$ & $4(7.5)$ & 0.847 \\
\hline
\end{tabular}




\section{Continued}

\begin{tabular}{|c|c|c|c|c|}
\hline Septic shock & $8(3.8)$ & $6(3.9)$ & $2(3.8)$ & 0.975 \\
\hline Postoperative infection & $4(1.9)$ & $4(2.6)$ & $0(0)$ & 0.238 \\
\hline Septic Abortion & $4(1.9)$ & $2(1.3)$ & $2(3.8)$ & 0.256 \\
\hline Chorioamnionitis & $1(0.5)$ & $1(0.6)$ & $0(0)$ & 0.136 \\
\hline $\mathrm{TVD}^{\mathrm{h}}$ & $6(2.8)$ & $3(1.9)$ & $3(5.7)$ & 0.162 \\
\hline Pulmonary embolism & $4(1.9)$ & $1(0.6)$ & $3(5.7)$ & 0.022 \\
\hline Amniotic embolism & $2(1)$ & $2(1.3)$ & $0(0)$ & 0.406 \\
\hline Anesthesia complications & $4(1.9)$ & $2(1.3)$ & $2(3.8)$ & 0.256 \\
\hline Indirect causes & $29(13.9)$ & $21(13.6)$ & $8(15.1)$ & 0.779 \\
\hline Encephalopathy & $7(3.4)$ & $4(2.6)$ & $3(5.7)$ & 0.283 \\
\hline Malaria & $3(1.4)$ & $2(1.3)$ & $1(1.9)$ & 0.753 \\
\hline Decompensated heart disease & $3(1.4)$ & $2(1.3)$ & $1(1.9)$ & 0.753 \\
\hline HIV-related complications & $2(1)$ & $0(0)$ & $2(3.8)$ & 0.015 \\
\hline Intestinal obstruction & $1(0.5)$ & $1(0.6)$ & $0(0)$ & 0.136 \\
\hline Trauma & $1(0.5)$ & $0(0)$ & $1(1.9)$ & 0.087 \\
\hline Autre ${ }^{\mathrm{i}}$ & $11(5.3)$ & $8(5.2)$ & $3(5.7)$ & 0.889 \\
\hline N.I ${ }^{j}$ & $4(2)$ & $3(1.9)$ & $1(1.9)$ & 0.982 \\
\hline
\end{tabular}

$\mathbf{a}=$ Yaounde Central Hospital $\mathbf{b}=$ Yaounde Gynaeco-Obstetric and Paediatric Hospital; $\mathbf{c}=$ Disseminated Intravascular Coagulation Consumptive Coagulopathy; $\mathbf{d}=$ Ectopic Pregnancy; $\mathbf{e}=$ HyperBlood Pressure; $\mathbf{f}$ $=$ Hemolysis Elevated Liver enzymes and low platelets; $\mathbf{g}=$ Acute oedema of the lung; $\mathbf{h}=$ Thromboembolic Venous Diseases. $\mathbf{i}=$ Necroticohemorrhagic Pancreatitis; Renal Neoplasia; Meningitis on Pregnancy; Meningitis; Ovarian Burkitt Lymphoma; Severe Hypokalemia; Seizure Disorder; Complications of Diabetes; Metastatic Breast Cancer; $\mathbf{j}=$ Not informed.

\subsection{Factors Contributing to Death and Fetal or Neonatal Prognosis (Table 5)}

Table 5. Distribution according to factors contributing to death and fetal or neonatal prognosis.

\begin{tabular}{ccccc}
\hline Contributing factors & $\begin{array}{c}\text { Total } \\
\text { N = 208 (\%) }\end{array}$ & $\begin{array}{c}\mathrm{YCH}^{\mathrm{a}} \\
\mathbf{N}=\mathbf{1 5 5}(\%)\end{array}$ & $\begin{array}{c}\mathrm{YGOPH}^{\mathrm{b}} \\
\mathbf{N}=\mathbf{5 3}(\%)\end{array}$ & P-value \\
\hline Contributing factors & & & & \\
Linked to the community & $41(20.9)$ & $33(22.7)$ & $8(15.8)$ & 0.347 \\
Linked to health services & $101(51.5)$ & $84(57.9)$ & $17(33.3)$ & 0.005 \\
Linked to both & $54(27.5)$ & $28(19.3)$ & $26(51)$ & 0.001 \\
No liability established & $12(6.1)$ & $10(7)$ & $2(3.9)$ & 0.734 \\
Fetal and neonatal prognosis & & & & \\
Alive & $78(37.5)$ & $57(36.8)$ & $21(39.6)$ & 0.712 \\
Deceased & $104(50)$ & $89(57.4)$ & $15(28.3)$ & $<0.001$ \\
N.I & $26(12.5)$ & $9(5.8)$ & $17(32.1)$ & $<0.001$ \\
\hline
\end{tabular}

$\mathbf{a}=$ Yaounde Central Hospital; $\mathbf{b}=$ Yaounde Gynaeco-Obstetric and Paediatric Hospital; $\mathbf{c}=$ Not informed. 
The majority of these factors contributing to the occurrence of maternal deaths were related to health services in 101 women who died, i.e. $51.5 \%$ with: $57.9 \%$ to $\mathrm{YCH}$ and $33.3 \%$ to YGOPH $(\mathrm{P}=0.005)$. Among the cases of maternal deaths reported, there were 104 cases of foetal or neonatal deaths, i.e. $50 \%$, with a significant difference in the 2 hospitals $(57.4 \%$ in $\mathrm{YCH}$ and $28.3 \%$ in $\mathrm{YGOPH}$; $\mathrm{P}<$ $0.001)$.

\section{Discussion}

\subsection{Frequencies}

The maternal mortality ratio of $\mathrm{YCH}$ is 2.5 times higher than that of $\mathrm{YGOPH}$ and 3.8 times higher than the national MM ratio of 406 per 100,000 LB [4]. While the maternal mortality ratio of YGOPH is 1.5 times higher than the national ratio. However, these ratios found in our two maternity wards are overestimated and do not reflect the reality of these services as they are centres that receive referrals from all over Yaoundé, and therefore it is difficult to extrapolate. Compared to other countries, these ratios are lower than those found by $\mathrm{Ab}$ dourhamane M. et al. in Mali and Garba M. et al. in Niger who found 2856.35 and 2640 per 100,000 LB respectively [5] [6].

\subsection{Socio-Demographic Characteristics}

The majority of the deceased women in our sample were between the ages of 30 and 34. Our rate is higher than those of Ahbibi A. in Morocco et al. and Tebeu et al. in the far north of Cameroon, which found $10 \%$ and $15.9 \%$ respectively for this same age group [7] [8]. Very few adolescent girls were affected by maternal mortality in our series, with a significantly higher rate in $\mathrm{YCH}$. These results could be explained by the fact that fertility among Cameroonian women in this age group remains high [4].

Married women and housewives made up the majority of deaths in our series. In fact, socio-economic level and marital status are known risk factors for maternal mortality [9] [10]. In our study, the care of women without income generating activities was largely dependent on a spouse who was often financially limited.

\subsection{Obstetrical Characteristics and Pregnancy Follow-up}

According to Bouhoussou MK et al. the incidence of maternal mortality increases as one moves from pauciparitis to multiparity, and from multiparity to high multiparity [11]. The average parity in the population in our study was $2.4 \pm 2.1$ with extremes ranging from 0 to 9. This result was similar to that of Ahbibi A. et al. [7], with almost half of the patients (42.8\%) having achieved no ANC. These were women who had generally not been detected for pregnancy-related conditions and were therefore at risk of maternal mortality. This rate is close to that of Samake S. et al. in Mali [12] who found $48.38 \%$ of cases. Unattended pregnancy is a risk factor. Several authors agree that antenatal care significantly reduces the maternal death rate [7] [10]. 


\subsection{Admission Context}

The majority of our sample was referred from the surrounding private health centres. This finding was similar to those of Ahbibi A. et al. in Morocco and Mayi-Tsonga S. et al. in Gabon [7] [13]. Referrals thus appear to be more incriminated in all the deaths recorded, due to the serious condition of the patients on their arrival, and would have contributed to increasing the MM ratio in these two hospitals. Moreover, the deceased patients had been evacuated, in most cases without accompanying measures. This could be due to the insufficient qualification of certain health workers working in the referral centres in the management of serious pathologies. This worsens the prognosis for the survival of these patients.

\subsection{Etiologies of Maternal Death}

The causes of maternal death in the 208 cases collected during our study were divided into two categories, according to the tenth revision of the International Classification of Diseases (ICD-10) [1]: Deaths by direct obstetric causes were by far the most frequent in $84.1 \%$ of cases, with a fairly constant rate in the two hospitals studied. Haemorrhage caused the most deaths, followed by hypertension and its complications, infections and complications of anaesthesia. More specifically; At YGOPH, the leading cause of maternal death was represented by hypertensive diseases and their complications, followed by haemorrhage. Whereas in $\mathrm{YCH}$, the leading cause of maternal death was represented by haemorrhage, followed by hypertensive diseases and their complications. This finding would suggest that haemorrhagic conditions would be better managed at YGOPH, whereas hypertensive conditions would be better managed at YCH. A number of African authors have made a similar observation [8] [13] [14]. These findings may be related to the low socio-economic status of the referred patients, lack of optimal antenatal follow-up or adequate surveillance during labour and postpartum, and sometimes also to the difficulty in obtaining blood for transfusion. From these figures, it appears that $\mathrm{YCH}$ has difficulties in managing hemorrages, while YGOPH has more difficulties in managing hypertensive diseases.

Encephalopathy was the leading indirect obstetric cause of maternal deaths in $3.4 \%$ of cases. This finding was different from those of Mayi-Tsonga S. and Tebeu PM. who found complications related to HIV infection in 31.25\% and 9.5\% of cases respectively. This could be explained by the significant regression in the prevalence of the infection.

\subsection{Factors Contributing to Death}

Although more pronounced at the HCY, it was found that slightly more than half of the cases of maternal death among those reported were related to the health services. This finding could be explained by the fact that the obstetrics and gynaecology unit at the $\mathrm{YCH}$ suffers from a considerable shortage of human resources, thus not allowing for prompt, efficient care and optimal monitoring. 
In addition, it was also noted that the blood bank in both hospitals was unable to provide the various blood products necessary for the management of critical cases.

\subsection{Limits of the Study}

The limitations of our study were essentially based on the poor maintenance and availability of the physical files of deceased patients. Indeed, the files in our hospitals are neither computerised nor always complete. As a result, they can be lost due to a poor archiving system, as is the case at the $\mathrm{YCH}$, or due to the fact that when there is a maternal death, the files are handled by a multitude of players.

\section{Conclusion}

The maternal mortality ratio remains very high in the two hospitals studied, with a relatively increasing trend over the last three years. More specifically, this ratio is 2.5 times higher at $\mathrm{YCH}$ than at YGOPH. Maternal mortality mainly concerned young, unemployed women. The absence of ANC is a factor favouring maternal mortality. The main aetiologies of maternal deaths were haemorrhages followed by hypertensive diseases and their complications. More specifically, these aetiologies were dominated by haemorrhage in YHC and hypertensive diseases in YGOPH. The majority of deaths were largely related to health services. Fetal and perinatal mortality was high in half of the cases. Most of these differences can be explained on one hand by the fact that the $\mathrm{YCH}$ is the largest reference center in the city, and on the other hand its human resources and its technical facilities are in deficit compared to the YGOPH. This highlights the weakness of our health system, which still requires a lot of improvements.

\section{Authors' Contributions}

Kamga designed the study, collected and analyzed the data. Kamga, Fouelifack, Fouedjio and Mesumbe wrote the manuscript. Foumane oversaw the process from conception to submission of the manuscript. All authors have read and approved the final version of the manuscript.

\section{Conflicts of Interest}

Authors do not declare any conflict of interest.

\section{References}

[1] OMS (1995) Classification Statistique Internationale des Maladies et des Problèmes de santé Connexes, Dixième révision. Organisation Mondiale de la Santé, Genève Vol. 2, 139-141.

[2] Alkema, L., Chou, D., Hogan, D., Zhang, S., Moller, A.B., Gemmill, A. et al. (2016) Global, Regional and National Levels and Trends in Maternal Mortality between 1990 and 2015, with Scenario Based Projections to 2030: A Systematic Analysis by the UN Maternal Mortality Estimation Inter-Agency Group. The Lancet, 387, 462474. https://doi.org/10.1016/S0140-6736(15)00838-7 
[3] Alastair, A., Shadi, S., Haja, W. and Sophie, W. (2017) Observatoire de la santé mondiale: La réduction de la mortalité maternelle dans les pays en développement. Bulletin de l'Organisation Mondiale de la Santé, 378, 12-30.

[4] Institut National de la Statistique (INS) et ICF (2020) Enquête Démographique et de Santé du Cameroun 2018. Yaoundé, Cameroun et Rockville, Maryland, USA : INS et ICF: 377-385.

[5] Abdourhamane, M. (2008) Etude de la mortalité maternelle dans le service de Gynéco-Obstétrique du CHU Gabriel Touré, de l'épidémiologie à l'audit. Thèse de Médecine, Bamako 2008-08M305 : 58-69.

[6] Garba, M., Nayama, M., Alio, A.P., Holloway, M.L., Hamisu, B.S. and Salihu, H.M. (2011) Maternal Mortality in Niger: A Retrospective Study in a High Risk Maternity. African Journal of Medicine and Medical Sciences, 40, 393-397.

[7] Ahbibi, A. (2015) La mortalité maternelle en réanimation obstétricale: Etude rétrospective de 123 cas. Thèse Med., Université Cadi Ayyad Faculté de Médecine et de Pharmacie de Marrakech, Marrakech.

[8] Tebeu, P.M., Ngassa, P., Kouam, L., et al. (2007) Maternal Mortality in Maroua Provincial Hospital, Cameroon (2003-2005). West Indian Medical Journal, 56, $502-$ 507.

[9] Romero-Gutiérrez, G., Espitia-Vera, A., Ponce-Ponce de León, A.L. and Huerta-Vargas, L.F. (2007) Risk factors of Maternal Death in Mexico. Birth, 34, 21-25. https://doi.org/10.1111/j.1523-536X.2006.00142.x

[10] Tajik, P., Nedjat, S., Afshar, N.E., Changizi, N., Yazdizadeh, B., Azemikhah, A., et al. (2012) Inequality in Maternal Mortality in Iran: An Ecologic Study. International Journal of Preventive Medicine, 3, 116-121.

[11] Bouhoussou, M.K., Djanhan, Y., Boni, S., Kone. N. and Toure, C.K. (1992) La Mortalité maternelle à Abidjan en 1988. Médecine d'Afrique Noire, 39, 480-484.

[12] Samake, S. (2004) Mortalité maternelle et l'Anesthésie Réanimation dans les services de gynécologie-obstétrique de l'HNPG, l'HNGT et le CS Réf Com V. Thèse de doctorat en medicine, Bamako, 35.

[13] Mayi-Tsonga, S., Ndombi, I., Oksana, L., Methogo, M., Diallo, T. and Mendome, G. (2008) Mortalité maternelle à Libreville (Gabon): état des lieux et défis à relever en 2006. Cahiers Santé, 18, 193-197. https://doi.org/10.1684/san.2008.0133

[14] Koudjou, T.L.B. (2008) Etude de la mortalité maternelle dans les services de gynécologie-obstétrique et d'anesthésie-réanimation au CHU du Point "G": À propos de 73 cas. Thèse Med., Faculté de Médecine, de Pharmacie et d'Odonto-Stomatologie, Bamako. 


\section{Survey Sheet}

Date: .../.../....

Date of patient's admission: .../.../....

\begin{tabular}{|c|c|c|c|}
\hline $\mathrm{N}^{\bullet}$ & Question & Answers's modalities & Code \\
\hline \multicolumn{4}{|c|}{ I-PATIENT IDENTIFICATION } \\
\hline 102 & Age group & $\begin{array}{l}1=15-19 ; 2=20-24 ; 3=25-29 \\
4=30-34 ; 5=\geq 35\end{array}$ & I I \\
\hline 105 & Level of education & $1=$ Analphabetic; $2=$ Primary level; $3=$ Secondary level; $4=$ Graduate study; $5=$ N.I & I_I \\
\hline 106 & Marital status & $\begin{array}{l}1=\text { Married; } 2=\text { Single } 3=\text { Divorced } 4=\text { Widowed } \\
5=\text { Concubine; } 6=\text { N.I. }\end{array}$ & I I \\
\hline 107 & Occupation & $\begin{array}{l}1=\text { Housewife; } 2=\text { Government employee; } 3=\text { Pupil; } 4=\text { Student; } 5=\text { Trade; } 6=\text { Dressmaker } \\
7=\text { Hairdresser; } 8=\text { Teacher; } 9 \text {-Call box; } 10=\text { Other...................... (Specify); } 11=\text { N.I }\end{array}$ & 1 \\
\hline \multicolumn{4}{|c|}{ II-ADMISSION CONTEXT } \\
\hline 208 & Time of entry & 1 & \\
\hline 209 & Receiving structure & $1=\mathrm{YGOPH} ; 2=\mathrm{YCH}$ & I_ \\
\hline 210 & Referring structure & $1=$ D.M.C; 2 = D.H; 3 = Private H.C; $4=$ Reference hospital; 5 = Faith-based HC; 6 = N.I & I I \\
\hline 212 & Mode of admission & $1=$ Self-referred; $2=$ Family-referred; $3=$ Referred; $4=$ Deceased; $5=2+3 ; 6=2+3+4$ & 1 \\
\hline 214 & Transport conditions & $1=$ Ambulance; $2=$ Taxi; $3=$ Personal car; $4=$ Other:....................... (Specify); $5=$ N.I & I I \\
\hline 215 & Pre-transfer nrenaration & a-PVL; 1 = Yes; 2 = No & I \\
\hline 210 & Pre-transter preparation & h-No treatment received; $1=$ Yes $2=$ No $3=$ N.D & I I \\
\hline \multicolumn{4}{|c|}{ III-OBSTETRIC AND PREGNANCY HISTORY } \\
\hline 320 & Gravida & $1=/ \_/ ; 2=$ N.I (Not informed) & I I \\
\hline 321 & Parity & $1=/ \_/ ; 2=$ N.I (Not informed) & I_ \\
\hline 324 & Term of current pregnancy & I__ /Week /___ I Days & \\
\hline 325 & ANCs & $1=\mathrm{Yes} ; 2=\mathrm{No}$ & 1 \\
\hline 326 & Number of ANCs & 1 & I \\
\hline \multicolumn{4}{|c|}{ IV-CLINICAL DIAGNOSIS } \\
\hline \multirow{13}{*}{430} & \multirow{13}{*}{$\begin{array}{l}\text { Diagnostic hypotheses and } \\
\text { evolution }\end{array}$} & a-Hypovolemic shock; $1=$ yes $2=$ no & I I \\
\hline & & b-Septic shock; $1=$ yes $2=$ no & 1 \\
\hline & & c-Ruptured Ectopic Pregnancy; $1=$ yes $2=$ no & 1 \\
\hline & & d-Disseminated Intravascular Coagulation (DIC); $1=$ yes $2=$ no & I \\
\hline & & e-Stroke; 1 = yes $2=$ no & 1 \\
\hline & & f-Post partum haemorrhage; $1=$ yes $2=$ no & I I \\
\hline & & g-Placenta Abruptio; $1=$ yes $2=$ no & I I \\
\hline & & h-Haemorrhagic placenta previa & I \\
\hline & & i-Severe pre-eclampsia; $1=$ yes $2=$ no & 1 \\
\hline & & j-Eclampsia; $1=$ yes $2=$ no & I I \\
\hline & & $\mathbf{k}$-Uterine rupture; $1=$ yes $2=$ no & 1 \\
\hline & & 1-Incomplete abortion; $1=$ yes $2=$ no & 1 \\
\hline & & m-Septic abortion; $1=$ yes $2=$ no & 1 \\
\hline
\end{tabular}




\section{Continued}

n-Peritonitis; 1 = yes 2 = no

o-Post-operative peritonitis; 1 = yes $2=$ no

p-Cardiopathy; 1 = yes 2 = no

q-Malaria in pregnancy; $1=$ yes $2=$ no

r-Severe anaemia; $1=$ yes $2=$ no

s-In utero Fetal Death; 1 = yes $2=$ no

t-Encephalopathy; $1=$ yes $2=$ no

u-Acute Lung Edema; 1 = yes $2=$ no

$\mathbf{v}$-Post abortum uterine perforation; $1=$ yes $2=$ no

w-Other; $1=$ yes $2=$ no

(if yes specify)

434 Duration of hospitalization

/ hours or /_/ days

\section{V-CIRCUMSTANCE OF DEATH}

546 Date of death

547 Time of death

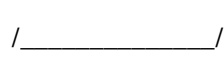

548 time to management

$1=$ I $/ ; 2=$ Not management

a-Pregnancy; $1=$ Yes $2=$ No

b-Delivery; 1 = Yes 2 = No

560 Period of death

c-Post-partum; 1 = Yes $2=$ No

d-Post-operative; 1 = Yes 2 = No

Vaginal Delivery route

Date

561

Moment of delivery

Active Management of the Third Period of Childbirth (AMTPC) done

562 Surgical intervention

563 Type of surgery

564 Date

565 Time

570 Condition of the newborn

572 Blood transfusion

573 Number of blood bags

574 Cause of death
e-Per-operative; 1 = Yes 2 = No

f-Post-abortum; 1 = Yes 2 = No

$1=$ Yes; 2 = No; 3 = Not specified

I

$1=$ Before admission; 2 = After admission

$1=$ Yes $; 2=$ No $3=$ N.I (Not informed)

$1=$ Yes $; 2=$ No

$1=$ Caesarean section; 2 = Laparotomy; $3=\mathrm{D} \& \mathrm{C} /$ Curettage;$$
\text { I }
$$

$1=1$ $/ ; 2=$ N.I (Not informed)

a-Alive; 1 = Yes 2 = No

b-Macerated; $1=$ Yes $2=$ No

c-Intrapartum death; $1=$ Yes $2=$ No

d-Neonatal death; $1=$ Yes $2=$ No

e-Not specified; $1=$ Yes $2=$ No

$1=$ Yes; 2 = No

I___ /

$1=$ Direct obstetric causes; 2 = Indirect obstetric causes. 


\section{Continued}

575 Direct causes

577 HBP

578 Thromboembolic disease

579 Infections

\section{Indirect obstetric cause}

580 Indirect causes

581 Supporting factors

\section{Causes obstétricales directes}

a-HBP; 1 = Yes 2 = No

b-Infection; 1 = Yes 2 = No

c-Hemorrhage; $1=$ Yes $2=$ No

d-Complications of anaesthesia; 1 = Yes 2 = No

e-Embolic diseases; 1 = Yes $2=$ No

f-Other; 1 = Yes 2 = No

If yes specify /

a-Uterine atony; 1 = Yes 2 = No

b-Cervical tears; 1 = Yes $2=$ No

c-DIC; $1=$ Yes $2=$ No

d-Uterine rupture; $1=$ Yes $2=$ No

e-Placenta praevia; $1=$ Yes $2=$ No

f-Placenta abruptio; $1=$ Yes $2=$ No

g-Abortion; 1 = Yes 2 = No

h-Ectopic Pregnancy; $1=$ Yes $2=$ No

i-Other; 1 = Yes 2 = No

If yes specify /

a-Pre-eclampsia; $1=$ Yes $2=$ No

b-Eclampsia; 1 = Yes 2 = No

c-HELLP syndrom; $1=$ Yes $2=$ No

d-Stroke; 1 = Yes 2 = No

g-Other; $1=$ Yes $2=$ No

If yes specify /

a-Pulmonary embolism; $1=$ Yes $2=$ No

b-Cerebral venous thrombosis; $1=$ Yes $2=$ No

c-Amniotic embolism; $1=$ Yes $2=$ No

a-Septic abortion; 1 = Yes 2 = No

b-Post-operative infection; $1=$ Yes $2=$ No

c-Puerperal sepsis; 1 = Yes $2=$ No

d-Septic shock; 1 = Yes 2 = No

e-Chorioamniotitis; $1=$ Yes $2=$ No

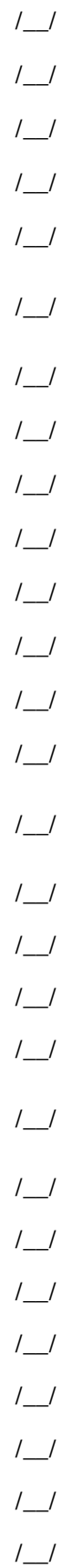

1 = Malaria; 2 = Decompensated heart disease; 3 = Valvulopathy; 4 = Intestinal obstruction;

5 = Severe pneumonia; 6 = Encephalopathy;

7 = Toxic; 8 = HIV-related complications;

$9=$ Trauma; $10=$ Other ..(please specify); $11=$ N.A (Not Applicable)

\section{Undetermined causes}

$1=$ Community related;

$2=$ Related to health services; $3=1+2$;

$4=$ No responsibility determined 


\section{Continued}

582 Community-related

583 Health service related
a-Situation seen as normal/safe by the woman/family; $1=$ Yes $2=$ No

b-Distant; 1 = Yes 2 = No

c-Road blocked; 1 = Yes $2=$ No

d-Transportation difficulties; $1=$ Yes $2=$ No

e-Money problem; 1 = Yes $2=$ No

f-None; 1 = Yes 2 = No

a-Drugs not available; $1=$ Yes $2=$ No

b-Dysfunction of blood banks; 1 = Yes $2=$ No

c-Non availability of means of emergency exploration; $1=$ Yes $2=$ No

d-Non availability of emergency transport facilities; $1=$ Yes $2=$ No

e-Insufficient health care personnel; $1=$ Yes $2=$ No

f-Delayed treatment at the health facility; $1=$ Yes $2=$ No

g-Underestimation of the woman's condition; $1=$ Yes $2=$ No

i-Inappropriate treatment decision; $1=$ Yes $2=$ No

j-Delay $/$ misdiagnosis; 1 = Yes 2 = No

k-Failure to monitor postpartum; $1=$ Yes $2=$ No

1-None; 1 = Yes 2 = No

\section{VIII-OTHER PARAMETERS}

